\title{
КЛИНИКО-ИММУНОЛОГИЧЕСКИЕ АСПЕКТЫ АДАПТАЦИИ ЖЕНЩИН К ВОЗРАСТНЫМ ИЗМЕНЕНИЯМ РЕПРОДУКТИВНОЙ СИСТЕМЫ
}

\section{И.Н. ЩЕРБИНА}

д.мед.н., профрессор, касредра акушерства и гинекологии №1 Харьковского национального медицинского университета

\section{Л.В. ПОТАПОВА}

д.мед.н., профессор, кафедра акушерства и гинекологии №1 Харьковского национального медицинского университета

\section{о.п. липко}

д.мед.н., профрессор, касредра акушерства и гинекологии №1 Харьковского национального медицинского университета
Перименопаузальный период наступает, как правило, на 50-м году жизни женщины, т.е. в момент наивысшего духовного и интеллектуального развития, когда она достигает профессиональной зрелости и наиболее востребована в обществе и семье. Этот период жизни одновременно сочетается с потерей генеративной функции и с инволютивными изменениями соматического плана [1, 2].

Фундаментальные исследования последних лет показали, что возникающий в перименопаузе дефицит половых стероидов обусловливает системные изменения в эстрогензависимых органах и тканях и является источником мощного стрессового фактора, вызывающего часто неадекватные адаптивные нарушения у женщин [3]. В связи с этим вызывает интерес то обстоятельство, что адекватный иммунный ответ обеспечивается определенным гормональным гомеостазом, и любые его изменения приводят $\mathrm{k}$ нарушению нормальной иммунологичской реактивности [4]. Параллельно происходящие возрастные дисфункциональные процессы в лимбической системе приводят к диспропорции моноаминов.

Цель нашего исследования заключалась в изучении состояния иммунной и симпато-адреналовой систем (САC) в патогенезе патологического течения перименопаузального периода.

\section{МАТЕРИАЛЫ И МЕТОДЫ ИССЛЕДОВАНИЯ}

Нами обследовано 315 женщин в возрасте 45-65 лет; из них 52 (16,5\%) пациентки - с физиологическим течением перименопаузального периода и 263 (83,5\%) - с различными клиническими фрормами перименопаузальных расстройств.

Из всего спектра перименопаузальных нарушений выделены четыре основных симптомокомплекса перименопаузального синдрома: нейровегетативные и психоэмоциональные, урогенитальные, метаболические, опорно-двигательные нарушения. С учетом этого обследованные женщины были разделены на 5 клинических групп. Первую клиническую группу (контрольную) составили 52 (16,5\%) пациентки с фризиологическим течением перименопаузального периода; вторую - 68 (21,6\%) лиц с нейровегетативными и психоэмоциональными нарушениями; третью - 70 (22,2\%) пациенток с урогенитальными нарушениями; четвертую $73(23,2 \%)$ женщины с метаболическими нарушениями, пятую - 52 (16,5\%) пациентки с опорно-двигательными нарушениями. В каждой группе степень тяжести клинических проявлений характеризовалась как легкое и тяжелое течение.

Клиническое обследование включало определение тяжести течения перименопазального синдрома на основании подсчета индекса Куппермана. Программа иммунологических исследований включала: определение популяционного и субпопуляционного состава лимфоцитов крови с помощью проточной лазерной цитометрии; активности фрагоцитарных клеток методом Е.У. Пастер и соавт. (1989). Методом иммунофрерментного анализа определяли содержание в крови основных про- и противовоспалительных цитокинов, аутоантител к РНК, ДНК, фосфолипидам и антигенам яичника, коллагену и эластину. Спектрофоотометрически изучали концентрацию в цервикальной слизи секретороного иммуноглобулина А и лизоцима, уровень основных классов иммуноглобулинов, тимического фактора (ТСФ) в крови. Определение содержания адреналина (А), норадреналина (НА) и досрамина (ДА) проводили в суточной моче путем колоночной хроматографии [5], серотонин в крови выявляли флюорометрическим методом [6], экскрецию мелатонина в моче - по методу Г.В. Зубкова и соавт. (1974) [7].

\section{РЕЗУЛЬТАТЫ И ИХ ОБСУЖДЕНИЕ}

При изучении характера иммунных реакций обнаружены существенные отличия в их течении в зависимости от клинической формы и степени выраженности перименопаузы.

У больных с нейровегетативными и психоэмоциональными нарушениями было выявлено, что в их развитии на первый план выступают нарушения в цитокиновом статусе. Так, в крови наблюдалось повышение содержания (в 5,1-7,3 раза) основных провоспалительных цитокинов интерлейкина (ИЛ)-1 $\beta$, ИЛ-6, фрактора некроза опухолей альфа (ФНО $\alpha)$, наиболее выраженное у пациенток с тяжелым течением. Имелась положительная корреляционная связь между степенью тяжести синдрома и содержанием провоспалительных цитокинов ИЛ- $1 \beta$ ( $r s=0,79)$, ИЛ-6 ( $r s=0,35)$, ФНО $\alpha$ ( $r s=0,46)$, ИНФ $\alpha(r s=0,61)$. У пациенток с тяжелым течением нейровегетативных нарушений достоверно снижалась концентрация противовоспалительных цитокинов (ИЛ-4, ИЛ-10). Выявленная 
взаимосвязь между цитокиновым профилем и степенью выраженности нейровегетативного синдрома свидетельствует о том, что взаимоотношения про- и противовоспалительных цитокинов могут указывать на тяжесть течения синдрома, а прогрессирующий рост этого показателя свидетельствует о неблагоприятном его течении.

Иммунологические изменения у пациенток с урогенитальным синдромом были сопряжены со снижением антимикробного иммунитета и нарушениями в системе фрагоцитарных клеток. Так, у этих больных достоверно были снижены: содержание Т-лимфоцитов (CD3+клеток) и Т хелперов (CD4+-клеток) в периферической крови; концентрация лизоцима и секреторного иммуноглобулина А в цервикальной слизи; фрагоцитарная активность лейкоцитов в крови. При анализе характера и степени иммунных нарушений в зависимости от тяжести урогенитальных расстройств было установлено, что при тяжелом течении их снижение было максимальным ( $<<0,05)$.

У женщин с метаболическими нарушениями характерными были расстройства в Т-системе иммунитета и механизмах иммунорегуляции, которые манифестировали на фоне ослабления гормональной фрнкции тимуса (log2 ТСФ 4,2 $\pm 0,3, p<0,05)$. Уровень ТСФ у пациенток с тяжелым течением был наиболее низким $(3,6 \pm 0,2)$. Тяжесть метаболических нарушений четко коррелировала (rs = -0,83) с уровнем ТСФ. Также в достоверно значимых количествах выявлялись аутоантитела к РНК, нативной и денатурированной ДНК, антифосфолипидные аутоантитела при тяжелом течении и аутоантитела к антигенам яичника. Появление в сыворотке крови аутоантител можно объяснить снижением надзорной функции иммунной системы и ответной ее реакцией на изменение нуклеинового и фосфолипидного обмена. Появляющиеся аутоантитела, по-видимому, направлены на нормализацию нарушенного иммунного статуса. Вырабатываемые антитканевые антитела не проявляют цитотоксических свойств в отношении клеток яичника, но могут привести к подавлению в них обменных процессов.

Иммунные расстройства у женщин с опорно-двигательными нарушениями протекают на фоне ослабления гормональной функции тимуса (log2 ТСФ 4,0 $\pm 0,3, p<0,05)$, а также выраженной тенденции к повышению сывороточного содержания молекул адгезии (ICAM-3 CD50+ - 634,5 \pm 70,2 и ICAM-1 CD54+- 103,5 \pm 20,9), снижению мононуклеаров (CD50+ - 31,6 \pm 3,4 и CD54+ - 23,9 \pm 3,6) при остеопении и достоверному повышению при остеопорозе. Это может являться фактором развития воспаления и аутоагрессивных иммунных реакций. Содержание растворимых форм молекул адгезии и мононуклеаров могут служить мар- керами тяжести течения нарушений опорнодвигательной системы. Сход молекул адгезии с поверхности остеокластов способен адгезировать тканевые макрофаги и индуцировать продукцию ими цитокинов с литическими свойствами, в результате вызывать дегенеративно-деструктивные процессы в костной ткани. На фооне дисфункции Т- и В-звена иммунитета обнаружено появление в крови аутоантител разной специфичности, что свидетельствует о расстройствах механизмов иммунорегуляции и развития аутоиммунных реакций. Отмечено повышение провоспалительных цитокинов, которые также усиливают резорбцию костной ткани.

При различных клинических фрормах перименопаузальной патологии также выявлены изменения содержания биогенных аминов, серотонина в крови и мелатонина в моче.

\section{у пациенток с нейровегетативными} и психоэмоциональными нарушениями прослеживается максимальная по сравнению с другими группами активация САС и серотонинергической системы ( $p<0,05)$, которые сопровождаются выраженной симпатикотонией, сопряженной со степенью тяжести данного синдрома. Имеется положительная корреляционная связь между степенью тяжести и содержанием A ( $r s=0,76)$, HA ( $r s=0,85)$ и ДА ( $r s=0,74)$. Продукция мелатонина снижена $(p<0,05)$ и имеет отрицательную корреляционную связь со степенью тяжести синдрома (rs = $-0,55)$. Низкий уровень мелатонина может привести к значительному повышению продукции гонадотропинов, что можно объяснить отсутствием ингибирующего воздействия гормона шишковидной железы на гипофиз.

Повышенное содержание катехоламинов $(\mathrm{A}=134,1 \pm 14,5 ; \mathrm{HA}=283,4 \pm 30,2$; ДА $=$ $1612,7 \pm 181,3)$ и серотонина $(0,631 \pm 0,09)$ сопровождается дисфункцией в Т-звене иммунитета, что обусловливает дисбаланс в цитокиновом статусе, а именно повышенную выработку провоспалительных цитокинов и сниженный уровень противовоспалительных цитокинов, что особенно характерно для пациенток с тяжелым течением нейровегетативных и психоэмоциональных расстройств.

У женщин с урогенитальными нарушениями отмечалось снижение активности серотонинергической системы и САС ( $<<0,05)$. Отмечена отрицательная корреляция (rs = -0,71) между степенью тяжести и содержанием ДА. С повышением степени тяжести происходит снижение индекса А/HА, что свидетельствует об угнетении адреналового звена в связи с нарушением метилирования адреналина. Это, по нашему мнению, связано с хроническим стрессом, возникающим на фоне длительного эстрогенного десицита, персистенции урогенитальной инфекции, дезорганизации

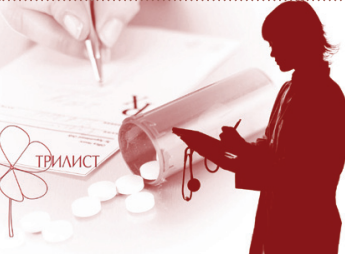

Результаты изучения состояния иммунной системы женщин перименопаузального периода показали, что с повышением степени тяжести перименопаузальных расстройств нарастают изменения иммунного статуса 


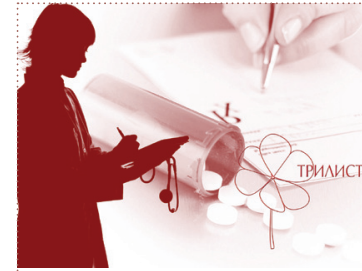

Возрастные изменения репродуктивной системы женщин развиваются на фоне дисбаланса досаминергической и серотонинергической систем и напряжения в системе иммунорегуляции. Все вышеуказанное, вероятно, приводит к истощению симпатоадреналовых и серотонинергических резервов. И чем тяжелее протекает синдром, тем ниже уровень биогенных аминов и более выражена степень угнетения фрормирования иммунных реакций.

Особенностью метаболических нарушений в перименопаузе является, с одной стороны, активация симпатического (продукция НА) и адренергического (А) звеньев САС. Наблюдаемое достоверное $(p<0,05)$ повышение содержания А и НА соответственно степени тяжести нарушений (A - rs = 0,63, HA - rs = 0,81) объясняется хроническим напряжением и снижением резервных возможностей САС. С другой стороны, на фоне хронического стресса и системных расстройств наблюдается уменьшение резервных возможностей САС, о чем свидетельствует достоверное снижение ДА $(p<0,05)$ соответственно степени тяжести метаболических расстройств ( $r s=-0,68)$. Обнаружена обратная корреляционная связь между содержанием НА и ДА $(r=-0,64)$ и ростом коэффициента НА/ДА. Гиперактивность САС сопровождается активацией стресслимитирующих серотонинергических механизмов. Концентрация серотонина была достоверно повышенной по сравнению с контрольными значениями $(\mathrm{p}<0,05)$ и зависела от степени тяжести метаболических нарушений ( $\mathrm{rs}=0,85)$. Активацию стресслимитирующей серотонинергической системы можно рассматривать как реакцию адаптации на патологический процесс.

Длительный хронический стресс на фоне эндокринно-обменной патологии приводит к угнетению работы центрального органа иммунной системы - тимуса [4]. В свою очередь дисфункция вилочковой железы негативно влияет на все звенья иммунной системы и механизмы ее контроля, о чем свидетельствует появление в сыворотке крови аутоантител.

у больных с опорно-двигательными нарушениями с прогрессированием десрицта оссификации наблюдается истощение дофаминергических возможностей. Происходит активация САС, в частности активация синтеза НА из ДА с увеличением коэфрфициента НА/ДА от 0,19 \pm 0,01 при остеопении до 0,43 \pm 0,03 при остеопорозе. Содержание ДА достоверно снижается $(p<0,05)$ соответственно степени тяжести нарушений (rs = -0,61). В этой группе пациенток отмечено резкое снижение концентрации серотонина в 1,3-2,5 раза и мелатонина в 1,6-2,5 раза, что, вероятно, происходит за счет низкого уровня эстрогенной активности яичников. Таким образом, активация А и НА на фоне угнетения продукции серотонина и мелатонина свидетельствует о максимальном напряжении защитно-приспособительных реакций организма. Снижение содержания серотонина и мелатонина уменьшает долю супрессорных клеток, что ведет к активности аутоиммунных реакций и подавлению антителообразования на фоне дисфункции В-звена иммунитета. В то же время снижение секреции ДА усугубляет депрессию иммунных реакций.

Угнетение активности дофраминергической системы и существенная разбалансировка механизмов иммунорегуляции, выражающаяся в повышении уровня провоспалительных цитокинов, усиливающих резорбцию костной ткани, и снижении противоспалительных цитокинов, угнетающих ее, можно объяснить с позиций патофизиологии хронического системного стресса.

\section{выводы}

Исследованием подтверждено наличие существенных отличий в общей иммунореактивности в зависимости от клинической фрормы перименопаузальных нарушений. С повышением степени тяжести перименопаузальных расстройств наблюдалось нарастание изменений в иммунном статусе. Перименопаузальные нарушения развиваются на фоне дисбаланса дофаминергической и серотонинергической систем, снижения функциональной активности эпиориза.

\section{ЛИТЕРАТУРА}

\section{1. Сметник В.П.}

Руководство по климактерию: Системные изменения, профилактика и коррекция климактерических расстройств / под ред. В.П. Сметник, В.И. Кулакова. - М.: Мед. инсрорм. агентство, 2001. - 685 С.

\section{2. Акунц К.Б.}

Менопауза / К.Б. Акунц. - М.: Триада-Х, 2004. - 78 с.

3. Гаспарян Н.Д.

Перименопауза критический период в жизни женщины / Н.Д. Гаспарян, А.В. Королева // Российский вестник акушера-гинеколога. - 2004. - № 3.

\section{4. Драннік Г.Н.}

Клінічна імунологія та алергологія: навчальний посібник / Г.Н. Драннік. - Одеса: Астропринт, 1999. - 604 с.

5. Матлина Э.Ш.

Метод определения адреналина, норадреналина, дофамина и ДОФА в одной порции мочи / Э.Ш. Матлина, 3.М. Киселева, И.Э. Сосриева // Матлина Э.Ш. Методы исследования некоторых гормонов и медиаторов / Э.Ш. Матлина, 3.М. Киселева, И.Э. Софиева. - М., 1965. - С. 25. 6. Кулинский В.И.

Определение серотонина в цельной крови человека и лабораторных животных / В.И. Кулинский, Л.С. Костюковская // Лабораторное дело. - 1969. - № 7. - С. 390394.

7. Зубков Г.В.

Метод определения (N-ацетил-5-метокситриптамина) В моче / Г.В. Зубков, В.Д. Петрушина, В.А. Чиниженко, А.А. Анискина // Сб. научных трудов ХМИ. - 1974. - Вып. 109. - C. 77-81. 